\title{
Democratizar a informação para o desenvolvimento do conhecimento: a ampliação do acesso ao acervo documental das ciências e da saúde na Fiocruz
}

\author{
Democratizing information to develop knowledge: expanding \\ access to the science and health document collection at Fiocruz
}

\section{Nercilene Santos da Silva Monteiro \\ Vice-Diretoria de Gestão e Desenvolvimento Institucional/ Fundação Oswaldo Cruz. Rio de Janeiro - RJ - Brasil orcid.org/0000-0002-1785-7022 nercilene.monteiro@fiocruz.br}

Recebido em 21 abr. 2017. Aprovado em 20 mar. 2018.
MONTEIRO, Nercilene Santos da Silva. Democratizar a informação para o desenvolvimento do conhecimento: a ampliação do acesso ao acervo documental das ciências e da saúde na Fiocruz. História, Ciências, Saúde Manguinhos, Rio de Janeiro, v.26, n.1, jan.-mar. 2019, p.299-318.

Resumo

A Fundação Oswaldo Cruz é detentora de expressivo patrimônio cultural constituído por coleções biológicas, edificações, objetos e documentos históricos qualificados como ativos estratégicos para preservação da memória institucional, para o ensino e para a pesquisa no campo das ciências e da saúde. No entanto, uma parte relevante do acervo documental estava indisponível para consulta pública até 2014. Este artigo apresenta o processo de disponibilização integral do acervo, descrevendo os problemas enfrentados, as soluções encontradas e os resultados obtidos. Ao final, a gestão dos documentos físicos e digitais é apontada como componente central para constituir fontes de informação para o presente e fontes históricas para o futuro.

Palavras-chave: acesso à informação; gestão de documentos; documentos digitais; fontes históricas; Casa de Oswaldo Cruz/Fiocruz.

\begin{abstract}
The Oswaldo Cruz Foundation is home to significant cultural heritage comprising biological collections, buildings, and historical documents and objects denoted as strategic assets for preserving institutional memory as well as for teaching and research in the field of science and health. However, a major portion of these collections was unavailable to the public until 2014. This article introduces the process involved in providing full access to these collections and describes the challenges, solutions, and results. Finally, the management of physical and digital documents is indicated as a central component in constituting sources of information for the present and historical sources for the future.
\end{abstract}

Keywords: access to information; document management; digital documents; historical sources; Casa de Oswaldo Cruz/Fiocruz.

http://dx.doi.org/10.1590/S0104-59702019000100017 
$\mathrm{O}$ desenvolvimento das Tecnologias da Informação e Comunicação (TIC) apoiou o progresso científico no século XX, resultando em uma mudança radical na maneira pela qual a ciência é produzida em alguns segmentos. A big science e a new big science $^{1}$ superaram o modelo individualizado de produzir conhecimento, cedendo lugar à descentralização mediada pelo uso de potentes plataformas que permitem a geração, a interpretação e o compartilhamento de um volume expressivo de dados entre grupos de pesquisadores, ampliando sobremaneira o potencial das descobertas, especialmente no campo biomédico.

Em um ritmo muito veloz, o conhecimento é registrado e acessado simultaneamente em diferentes partes do mundo, modificando também a forma pela qual as fontes de informação deverão ser constituídas e preservadas no presente, para serem acessadas no futuro.

Tais fontes de informação são, em sua maioria, fontes primárias e constituem os acervos arquivísticos encontrados nos laboratórios. São documentos textuais, imagens, coleções científicas, dados registrados em bases tecnológicas, mensagens eletrônicas, enfim, variados gêneros de documentos que representam a memória institucional e a memória de grupos e de pessoas "que devem ser preservadas e acessíveis às gerações atuais e futuras como testemunhos da atividade humana que a produziu, e como objetos de reflexão e fonte de pesquisa" (COC, 2013, p.8).

Para garantia da preservação e do acesso a essas fontes, a implantação da gestão de documentos físicos e digitais é fundamental. Na Fundação Oswaldo Cruz (Fiocruz), a política de gestão de documentos foi implantada por meio do Sistema de Gestão de Documentos e Arquivos (Sigda), ${ }^{2}$ criado na década de 1990. Coordenado pela Casa de Oswaldo Cruz (COC), o Sigda é um conjunto de diretrizes e práticas formuladas por um comitê técnico composto por profissionais das diversas unidades da Fiocruz. O sistema cumpre papel importante na integração das ações de gestão da informação e gestão do acervo histórico, atuando desde a fase da produção do documento até sua destinação final.

Apesar da existência da política, as práticas da gestão documental ainda não estão plenamente adotadas na área finalística da instituição. Santos (2012) observou que, em um dos laboratórios de pesquisa biomédica, os pesquisadores faziam anotações em arquivos pessoais, reduzindo o potencial de abordagens historiográficas que podem ser desenvolvidas a partir de pesquisas realizadas em registros oficiais, como os cadernos de protocolo, por exemplo. ${ }^{3}$

A situação observada nesse laboratório possivelmente se reproduz em outros espaços institucionais, demonstrando fragilidades na gestão e preservação de fontes de informação, mesmo em instituições que possuem políticas arquivísticas formalmente estabelecidas.

Pensar sobre essa realidade nas universidades, nos centros e instituições de pesquisa nos remete a refletir sobre as dificuldades pelas quais os estudiosos do campo da história das ciências e da saúde passarão para recuperar os bastidores das pesquisas. Como poderão obter informações que estão disponíveis em registros informais dispersos? Como poderão acessar dados registrados em meios eletrônicos? Enfim, como recuperar informações para reconstruir socialmente e democratizar o conhecimento sobre as inovações científicas deste século?

Tais reflexões evidentemente transcendem a uma única disciplina, exigindo o esforço integrado entre pesquisadores, analistas, arquivistas, historiadores e profissionais das 
tecnologias da informação para definir novos conceitos, métodos e ferramentas para preservação dos documentos físicos e digitais. No campo da arquivologia, por exemplo, Ribeiro (2012) ressalta que os conceitos de fundo, proveniência e gestão de documentos da arquivologia tradicional mostram-se inadequados para responder à nova realidade informacional, merecendo revisões e reformulações.

Ao mesmo tempo que profissionais empreendem esforços para superação de lacunas de conhecimento e indefinições tecnológicas da era digital, a maioria das organizações de custódia precisa, ainda, superar o desafio da preservação e da disponibilização da documentação física.

É no campo do acesso ao acervo físico que este artigo pretende contribuir, apresentando o projeto que resultou na disponibilização de todo acervo histórico textual acumulado em trinta anos pela Fundação Oswaldo Cruz. Começa por uma breve contextualização da história da Fiocruz e da criação da unidade responsável pela preservação do acervo histórico arquivístico. Em seguida, descreve os esforços iniciais para constituição desse acervo e os problemas identificados acerca da indisponibilidade de parte da documentação. O desenvolvimento da solução encontrada, a métrica de acompanhamento e os resultados obtidos estão descritos com a finalidade de apoiar instituições que passam por problemas similares na gestão do acervo histórico.

\section{A história como amálgama institucional}

A trajetória institucional da Fundação Oswaldo Cruz justifica sua longevidade. Uma longa história de luta e superação de desafios que tem início em 1899, quando Oswaldo Cruz foi convidado pelo barão de Pedro Afonso para trabalhar no combate da peste bubônica no futuro Instituto de Sorologia. Em 1902, Oswaldo Cruz assumiu o instituto e, inspirado no Instituto Pasteur (França), criou um modelo organizacional integrando as atividades de produção, pesquisa e ensino. O Instituto recebeu reconhecimento de suas atividades de pesquisa, passando a se chamar Instituto de Patologia Experimental de Manguinhos em 1907, e em seguida foi renomeado em homenagem a Oswaldo Cruz, passando a denominar-se Instituto Oswaldo Cruz (IOC) em 19 de maio de 1908 (Ponte, 29 out. 2015).

O instituto apresentava alto desempenho, e suas realizações foram reconhecidas nacional e internacionalmente. A atuação para solucionar os problemas de saúde da população traduzia seu papel público de forma inequívoca e sua contribuição na formulação e implementação de políticas públicas para o desenvolvimento urbano da capital brasileira - na época Rio de Janeiro - tornava o instituto central para as ambições políticas. Para sustentabilidade das atividades, o Instituto de Sorologia prestava serviços e produzia inovações tecnológicas que garantiam um conjunto diversificado de receitas, destacandose a "verba da Manqueira".

No campo científico, os investimentos na pesquisa abriram novas possibilidades para a ciência brasileira, atraindo jovens médicos das universidades. A formação de quadros qualificados ${ }^{5}$ era garantida pelo curso de Aplicação de Manguinhos - requisito obrigatório para o ingresso na carreira de pesquisa do instituto. 
A morte de Oswaldo Cruz, em 1917, criou as primeiras crises do instituto. As disputas internas pela sucessão e a nomeação de Carlos Chagas em detrimento de candidatos como Figueiredo Vasconcellos e Cardoso Fontes deixaram marcas e ressentimentos (Costa, 2014) que inviabilizaram a revitalização do projeto institucional quanto às novas demandas sanitárias surgidas a partir das mudanças demográficas e epidemiológicas da população brasileira.

Externamente, com a recessão da década de 1920, o instituto amargou redução de receitas em função da inflação e da alta dos preços, que impactava seu custo de produção. Politicamente, enfrentava ataques do Ministério da Agricultura contra a produção de insumos veterinários e disputas com oligarquias locais atentas aos resultados das expedições dos cientistas pelo interior do país (Costa, 2014), o que potencializava as dificuldades da gestão de Chagas. A insatisfação interna com sua gestão se intensificou quando quadros importantes foram proibidos de realizar atividades comerciais e tiveram que cumprir controles de assiduidade, medidas adotadas para conter o que a imprensa chamava de "comercialização da ciência".

Com a morte de Carlos Chagas, em 1934, Cardoso Fontes assumiu a diretoria e conseguiu manter o protagonismo do instituto em projetos no campo da saúde durante o primeiro período do governo de Getúlio Vargas. As campanhas da época de Oswaldo Cruz foram retomadas, e o instituto atuou de forma exitosa em 1934 e 1937 no combate à hanseníase e ao surto de febre amarela. Internamente, permanecia o cenário de disputas, mágoas e ausência de projeto institucional que mais à frente resultará na decadência do Instituto de Sorologia.

Segundo Ponte (29 out. 2015), os períodos subsequentes marcariam um forte declínio no desempenho institucional por falta de investimentos, disputas internas e políticas de caráter privatizante na área da saúde. Se, por um lado, o modelo implantado durante o Estado Novo criava condições para o desenvolvimento econômico e social no Brasil, por outro, as medidas centralizadoras de 1937 promoveram mudanças radicais na gestão do instituto. A proibição da comercialização de produtos e da arrecadação direta dos royalties eliminou a autonomia de gestão de aproximadamente 30\% das receitas do IOC. Nesse mesmo período, ocorreu a proibição da produção de produtos veterinários e a centralização do orçamento do governo federal, com a obrigatoriedade da devolução dos saldos anuais, inviabilizando o reinvestimento e a expansão de atividades. Essas mesmas políticas proibiram a acumulação de cargos, causando a perda de quadros qualificados e dificuldades para formação de novos quadros.

Em 1942, Henrique Aragão assumiu o instituto e, aproveitando o impulso industrial durante a Segunda Guerra Mundial, conseguiu atrair importantes recursos para instalação de fábrica para produção de medicamentos, assim como recursos para construir e equipar novos laboratórios. Divergências contra a transferência de instalações fabris financiadas pela Fundação Rockefeller provocaram sua renúncia em 1949. Nos períodos seguintes, o IOC seguiu sem lideranças políticas capazes de produzir a coesão interna para um novo projeto institucional.

Durante os governos de Vargas e Juscelino, a política econômica adotou soluções desenvolvimentistas, focando na industrialização brasileira e em reformas sociais. 
Manguinhos não reagiu durante o período de pujante investimento estatal em atividades industriais. Também não mostrou força diante das políticas privatistas implementadas no campo da atenção à saúde, quando o modelo definido pela Previdência Social privilegiava a contratação e os convênios com a rede privada de serviços ambulatoriais e hospitalares.

Em 1953, foi criado o Ministério da Saúde, e o instituto tornou-se uma estrutura de terceiro escalão no âmbito do Estado brasileiro, tendo como principal atividade a produção de vacinas e as campanhas sanitárias. Os investimentos federais estavam direcionados para a pesquisa aplicada, em detrimento da pesquisa básica.

Sem investimentos, desprestigiado e fragmentado internamente, o instituto sofreu seu maior golpe durante o regime militar de 1964, quando foram abertos inquéritos com o objetivo de identificar opositores ao governo. Após suposta apuração, foi editado decreto em abril de 1970 suspendendo os direitos políticos dos cientistas Haity Moussatché, Herman Lent, Moacyr Vaz de Andrade, Augusto Cid de Mello Perissé, Hugo de Souza Lopes, Sebastião José de Oliveira, Fernando Braga Ubatuba e Tito Arcoverde Cavalcanti de Albuquerque. Dois dias depois, esses oito cientistas e também Masao Goto e Domingos Arthur Machado Filho foram aposentados compulsoriamente. Mesmo sem a confirmação das suspeitas, todos foram afastados de suas atividades no episódio conhecido como o "massacre de Manguinhos" (Lent, 1978).

Com projetos e linhas de pesquisa comprometidos, o instituto sofreu novo revés ao ter estrutura e finalidade completamente desfiguradas em 1970, com a incorporação de instituições com trajetórias próprias, até então vinculadas ao Ministério da Saúde. ${ }^{6}$ Em seguida o Instituto Oswaldo Cruz foi transformado em Fundação Oswaldo Cruz (Fiocruz), tornando-se fundação pública de direito privado. ${ }^{7}$

O momento era de grande desorganização política - o que inviabilizava o planejamento integrado entre as atividades que existiam e as atividades que foram incorporadas. Esse quadro persistiu até 1975, quando Vinícius da Fonseca foi nomeado dirigente da fundação. Avaliando que a instituição havia se afastado das grandes questões nacionais (Azevedo, Hamilton, 2001), Vinícius implementou um planejamento pragmático, priorizando recursos para as pesquisas sobre a doença de Chagas, esquistossomose, hanseníase e doenças do grupo materno-infantil. Extinguiu o Instituto de Produção de Medicamentos (Ipromed) e criou Bio-Manguinhos e Farmanguinhos para produção de vacinas, derivados e medicamentos em grande escala (Ponte, 2007).

No final dos anos 1980, os movimentos pela redemocratização cresceram no Brasil, e a Fiocruz alcançou novo protagonismo nacional com Sérgio Arouca, que, junto com Hésio Cordeiro, liderou o movimento pela reforma sanitária, resultando na criação do Sistema Único de Saúde (SUS). Internamente, Sérgio Arouca criou o Congresso Interno - instância estratégica e inovadora no âmbito da gestão pública - e viabilizou as condições políticas para aprovação de eleições internas de seus dirigentes.

Atualmente, a Fiocruz tem sua estrutura organizacional e seu modelo de governança consolidados. Integra, reconhece e valoriza a diversidade das atividades desenvolvidas por 21 unidades científicas instaladas em nove estados brasileiros e um escritório técnico instalado em Moçambique, na África. 


\section{A preservação da história das ciências e da saúde}

A Casa de Oswaldo Cruz (COC) foi criada pela Fiocruz em 1986, com a finalidade de constituir, preservar e compartilhar conhecimento no campo da história das ciências e da saúde, adotando a pesquisa, a educação, a preservação do patrimônio cultural e a popularização da ciência como elementos centrais.

Iniciou as atividades de constituição do acervo documental com um pequeno e engajado grupo de profissionais - historiadores, documentalistas e bibliotecários que foram responsáveis pela tarefa de localizar, identificar e reunir documentos, abrindo caminho para organização do atual Departamento de Arquivo e Documentação (DAD).

Priorizando a documentação institucional, o primeiro levantamento foi realizado no setor de hanseníase do Departamento de Medicina Tropical do Instituto Oswaldo Cruz (IOC), escolhido em razão da diversidade de suas atividades, que incluía pesquisa, prestação de serviços ambulatoriais e produção de reagentes, representando um conjunto importante dos processos de trabalho realizados pela Fiocruz (COC, 1986-2015).

A partir da constituição das primeiras fontes históricas, a COC recorreu às agências de fomento para financiamento da atividade de organização dos documentos. A relevância do acervo foi reconhecida por financiadores externos, e com a chegada dos primeiros recursos foram realizados os projetos "Tratamento e ampliação do acervo iconográfico do Museu Instituto Oswaldo Cruz" e "Guia de fontes para a história da saúde pública" (COC, 1986-2015).

Ainda neste período, foi realizado o projeto para "Constituição de acervo de depoimentos orais sobre a história da Fundação Oswaldo Cruz e das práticas de saúde pública", por meio do qual foi possível identificar arquivos pessoais e institucionais, destacando-se "os arquivos dos cientistas Oswaldo Cruz e Carlos Chagas e os negativos de vidro do Fundo Instituto Oswaldo Cruz - IOC (1903-1946), reconhecidos como patrimônio documental da humanidade pelo Programa Memória do Mundo da Unesco, em 2007, 2008 e 2012, respectivamente" (COC, 2013, p.12).

Atualmente, o acervo da Fiocruz contempla 113 fundos e 14 coleções de documentos textuais, iconográficos, cartográficos, micrográficos, sonoros, filmográficos e tridimensionais que remontam ao ano de 1803.

São fontes de informações produzidas e acumuladas pela Fundação Oswaldo Cruz, que incluem o patrimônio documental dos institutos que a constituíram em 1970, os quais já possuíam trajetórias expressivas, como é o caso do Instituto Oswaldo Cruz, além daqueles que a compõem atualmente. $\mathrm{O}$ acervo abrange também arquivos de cientistas, médicos e outros profissionais que se destacaram em suas áreas de atuação e parcelas de arquivos de instituições com atividades nas áreas da saúde e das ciências biomédicas que foram doadas ao DAD. Estão também incluídas nesse âmbito as coleções de documentos, assim chamadas por terem seu contexto de produção desconhecido ou por terem sido reunidas com base em uma temática específica (COC, 2009, p.14).

\section{A importância da gestão documental para constituição de fontes históricas}

As organizações precisam tomar decisões, produzir os meios probatórios de suas atividades e preservar a memória institucional. Para acessar as informações que darão 
suporte a essas ações é preciso implementar os requisitos de gestão arquivística desde a produção do documento até sua destinação final. Esses requisitos garantirão a preservação dos documentos físicos e/ou digitais, ao longo do tempo, e o acesso às informações em momento oportuno.

Segundo o Arquivo Nacional - órgão da administração pública federal responsável por implementar e acompanhar a política nacional de arquivos -, denomina-se "gestão documental" o conjunto de procedimentos e operações técnicas referente a produção, tramitação, uso, avaliação e arquivamento dos documentos em fase corrente e intermediária, visando à sua eliminação ou ao recolhimento para guarda permanente (e-ARQ Brasil, 2011).

Desse conjunto de procedimentos, Bernardes (1998) destaca que a avaliação deve ser realizada no momento da produção do documento, de modo a evitar a acumulação desordenada, que é o grande problema dos arquivos centrais ou intermediários, especialmente no serviço público. A produção de documentos não classificados ou classificados de forma errônea é o principal motivo para formação de massas documentais, assim designadas porque "abrangem períodos extensos, perfazem um volume considerável, não têm organização prévia e abordam as mais diversas atividades da instituição" (Cruz, 2013, p.28-29).

As massas documentais constituem um sério problema para as organizações de custódia. Um levantamento realizado no Instituto dos Arquivos Nacionais de Portugal, por exemplo, revelou a existência de $700 \mathrm{~km}$ de massa documental. Sobre esse levantamento, Ribeiro (14 jan. 2004) critica o que denominou "política incorporacionista", que seria o recolhimento de documentos sem tratamento prévio.

Para a autora, esse tipo de recolhimento transfere a responsabilidade do tratamento da documentação do produtor para os arquivos centrais, que ficam abarrotados. Argumenta que, mesmo que houvesse centenas de profissionais capazes de avaliar, selecionar, descrever, indexar e disponibilizar esses $700 \mathrm{~km}$ de documentos, quando esses procedimentos estivessem concluídos, outras centenas de quilômetros já estariam novamente acumulados de maneira desordenada.

Naturalmente, os recolhimentos de acervos relevantes, independentemente de suas condições, deverão ser mantidos. No entanto, as instituições de custódia não devem recolher apenas sob o prisma da salvaguarda, já que a expectativa é de que os documentos sejam disponibilizados à consulta pública como forma de manter vivos os legados, despertar novos interesses dos pesquisadores, estudantes, jornalistas e público em geral.

Nesse sentido, essas organizações precisam implementar políticas de incorporação de acervo que incluam ações de organização e disponibilização, do contrário estarão sempre abarrotadas de acervos indisponíveis, o que as tornará depósitos sem nenhuma relação com a história e com a geração do conhecimento na sociedade.

\section{O problema do acervo indisponível na Casa de Oswaldo Cruz}

O compromisso com a salvaguarda da memória explica a razão de recolhimentos em escala muito maior do que a capacidade interna de organização. Os pesquisadores responsáveis pelos primeiros recolhimentos na COC justificam que "em sociedades ou 
campos de atividade humana com pouca tradição arquivística ou historiográfica, a ausência de rotinas para o tratamento da massa documental termina por expô-la ao soterramento, culminando por estender amplas zonas de sombra sobre o passado" (Pires-Alves, Santos, Hamiltom, jul.-out. 1994, p.145).

Esses pesquisadores afirmam que, nessas condições, a atividade de arquivologia se aproxima da ideia de resgate. Isso, portanto, explica por que a maioria das instituições de custódia possui um importante quantitativo de acervo não organizado, mas certamente não justifica que a situação se perpetue e que prive o público do relacionamento com esses documentos, sendo necessário reconhecer que o acervo indisponível é uma inconformidade, um problema que ameaça a competência e a finalidade dessas instituições.

Na Fiocruz, a implantação do Sigda na década de 1990 deveria ter colaborado para evitar a formação de massas documentais nos fundos institucionais; no entanto, observa-se que a gestão documental avançou mais em áreas administrativas e em unidades ou setores de unidades em que a natureza da atividade exige o cumprimento de regras de certificação da qualidade, onde a gestão de documentos é um dos requisitos. Mesmo quando o Sigda se tornou uma política institucional obrigatória em 2009, a implantação da gestão arquivística continuou assimétrica e até mesmo desconsiderada nas estratégias da maioria das unidades.

Nesse cenário, a maior parte do acervo institucional recolhido configura uma grande massa documental que permaneceu inacessível ao público, apesar dos esforços iniciais para obter financiamento externo para sua disponibilização.

Ao tomar conhecimento da existência do conjunto de fundos indisponíveis para consulta pública, partiu da área de gestão a proposta de discussão sobre soluções viáveis para organizar toda a parcela indisponível. Após alcançar o consenso de que o quantitativo de fundos e coleções indisponíveis configurava um problema grave para o cumprimento da missão da COC, foi realizado levantamento para uma solução interna que resultou na estimativa de aproximadamente trinta anos para organizar todos os fundos e coleções, se nenhum profissional se afastasse e se o departamento não recebesse novos arquivos.

Essa constatação não paralisou a discussão, ao contrário, colocou o problema exatamente em sua dimensão: no ritmo que estava dado, somente a próxima geração teria acesso àquele conjunto valioso de informações.

No ano de 2010, a Casa de Oswaldo Cruz adotou a prática de elaborar o orçamento anual a partir de projetos que apresentassem iniciativas inovadoras, criando um portfólio de projetos estratégicos que foram descritos no Plano Quadrienal de 2010-2014. O modelo de planejamento determinava que as despesas básicas para custear as atividades de rotina ficariam garantidas para todos os setores, entretanto, recursos adicionais deveriam estar justificados por projetos que agregassem valor aos produtos e serviços disponibilizados ao público.

Por atender a essa premissa, o projeto de organização do acervo textual foi aprovado, sendo contratada uma empresa exclusivamente para executar o processamento técnico de 1.500 caixas de documentos textuais (cerca de um milhão de folhas) que abrangiam o período de 1803 a 2007, registrar as descrições arquivísticas e disponibilizar todos os inventários na Base Arch, repositório de acesso on-line de informações das ciências biomédicas e da saúde no Brasil. 
Coube ao DAD desenvolver os dados técnicos da contratação, definindo o escopo do projeto, a descrição das atividades, o perfil da equipe, as normas técnicas e metodológicas e a produtividade mensal esperada. O contrato foi iniciado em 2011, com vigência programada para 36 meses com a definição de atividades expressa no Quadro 1.

Quadro 1: Distribuição de responsabilidades entre as equipes executoras

\begin{tabular}{|c|c|}
\hline Equipe interna & Equipe externa \\
\hline 1. Definir as etapas referentes ao tratamento técnico; & $\begin{array}{l}\text { 1. Selecionar, de acordo com as instruções, o conjunto a } \\
\text { ser tratado; }\end{array}$ \\
\hline 2. Definir as formas de inclusão na base de dados; & 2. Identificar os documentos integrantes do conjunto; \\
\hline 3. Treinar os profissionais; & 3. Classificar e ordenar de acordo com o manual; \\
\hline $\begin{array}{l}\text { 4. Acompanhar diariamente o cumprimento dos } \\
\text { requisitos normativos; }\end{array}$ & $\begin{array}{l}\text { 4. Descrever os diferentes itens do acervo de acordo com } \\
\text { o suporte e a contextualização histórica do documento; }\end{array}$ \\
\hline $\begin{array}{l}\text { 5. Acompanhar diariamente o cumprimento dos } \\
\text { requisitos metodológicos; }\end{array}$ & 5. Conferir as descrições; \\
\hline $\begin{array}{l}\text { 6. Verificar a consistência das informações registradas na } \\
\text { base on-line; }\end{array}$ & $\begin{array}{l}\text { 6. Digitar as informações na base de dados de acordo } \\
\text { com o manual; }\end{array}$ \\
\hline 7. Realizar o controle de produtividade. & 7. Cumprir produtividade mensal pactuada em contrato. \\
\hline
\end{tabular}

Fonte: elaborado pela autora.

Para segurança do acervo, o serviço foi executado nas dependências da COC, sendo disponibilizados espaço físico, mobiliário, materiais de consumo e equipamentos. A equipe interna foi composta por uma arquivista experiente em organização de arquivos permanentes e dois historiadores experientes nas linhas do acervo. Essa equipe contou com o apoio da área de Gestão de Contratos, que realizou todos os controles e monitoramentos em relação aos aspectos administrativos e legais decorrentes da prestação do serviço.

\section{Execução do projeto}

O edital de licitações determinava que as empresas apresentassem atestado de capacidade técnica comprobatório da realização de serviço semelhante em características, quantidades e prazos ao que estava proposto no projeto.

A empresa que venceu a licitação estava estabelecida na Bahia e não dispunha de mão de obra para prestar serviço no estado do Rio de Janeiro. O que poderia ser um grande problema acabou sendo uma ótima oportunidade, porque a COC - como formadora de competências no campo da história das ciências e da saúde - pôde disponibilizar o cadastro de diversos profissionais, viabilizando a contratação de equipe qualificada.

Para o controle da produtividade, foi previsto um modelo de relatório de prestação de serviços que contemplava dados sobre a produtividade mensal, qualidade do serviço e eventuais inconformidades. O regime de execução adotado foi a empreitada por preço unitário - regime em que são pagos apenas os serviços efetivamente executados, 
descontando-se as ausências de pessoal, os insumos não repassados à mão de obra e os valores glosados por problemas na qualidade ou no prazo dos serviços, segundo critérios indicados no Acordo de Nível de Serviços.

Os recursos que financiaram as despesas do projeto foram separados das demais despesas do departamento, para que não se dispersassem em outras necessidades e também para que não se incorporasse ao orçamento de maneira permanente. Desse modo, o projeto trouxe impacto orçamentário expressivo nos anos de 2012 e 2013, tendo seu valor totalmente expurgado a partir de 2014, quando foi concluído.

\section{Monitoramento do projeto}

A organização do acervo histórico documental sempre foi monitorada; no entanto, o acompanhamento adotava como meta anual a organização de metros lineares de documentos. Esse tipo de monitoramento não deixava claro quando o acervo completo estaria disponível e não possibilitava a comparação entre o quantitativo de fundos e coleções sob a guarda da COC e o quantitativo disponível para o público, sendo, portanto, uma métrica de processo, e não de resultado.

Com a implantação do projeto, o critério de monitoramento foi revisto com o objetivo de acompanhar a evolução anual da disponibilidade do acervo para consulta pública. $\mathrm{O}$ monitoramento do desempenho tomou por base o padrão 6ES, definido no programa Gespública (19 jun. 2010, p.19), conforme o indicador no Quadro 2.

Quadro 2: Evolução da disponibilidade do acervo

\begin{tabular}{|l|l|l|l|l|l|}
\hline Dimensão & Significado & Unidade de medida & Sentido ideal & Meta & Fórmula \\
\hline Eficácia & $\begin{array}{l}\text { Evolução da } \\
\text { disponibilidade }\end{array}$ & Fundos & $\begin{array}{l}\text { Quanto maior } \\
\text { melhor }\end{array}$ & $\begin{array}{l}\text { Ampliar percentual } \\
\text { ao ano }\end{array}$ & $\begin{array}{l}\text { (N. de fundos } \\
\text { disponíveis/n. total } \\
\text { de fundos) }{ }^{*} 100\end{array}$ \\
\hline
\end{tabular}

Fonte: elaborado pela autora.

\section{Resultados do projeto}

O benefício direto alcançado com a realização do projeto diz respeito à organização, à sistematização e à publicação de um amplo conjunto de informações referente à história das ciências biomédicas e da saúde pública brasileira por meio dos registros documentais.

Foram disponibilizados todos os fundos que estavam indisponíveis (Anexo 1) em três anos de trabalho, podendo ser citados, apenas como exemplo, os fundos pessoais dos pesquisadores Haity Moussatché e Herman Lent, que integraram o grupo dos dez cassados no "massacre de Manguinhos". Também podemos destacar a disponibilização do fundo pessoal de Szachna Eliasz Cynamon, engenheiro sanitarista atuante na área de saúde ambiental e fundador da Cooperativa dos Trabalhadores Autônomos do Complexo de Manguinhos - Cootram (19942002). A organização desse fundo despertou o interesse de uma das alunas do Programa de Pós-Graduação em História das Ciências e da Saúde, que defendeu sua dissertação de mestrado em 2017 sobre essa importante iniciativa entre a Fiocruz e os moradores de Manguinhos para geração de emprego e renda na região. 
Ainda no campo do desenvolvimento de políticas sociais, podemos destacar a disponibilização do fundo da nona Conferência Nacional de Saúde - cujo tema foi "Saúde: municipalização é o caminho" -, que desenvolveu as diretrizes para implantação efetiva do SUS, estabelecendo os principais mecanismos para seu financiamento e controle social.

A organização do acervo permitiu a elaboração de inventários on-line, organizados por menus, garantindo uma visão geral do acervo. Essa organização modificou a forma de busca dos usuários, que têm demonstrado preferência pelos conjuntos institucionais em detrimento dos fundos pessoais - até então os mais consultados. Também houve uma importante ampliação no acesso à Base Arch, subindo de 946 acessos em 2010 para 6.932 em 2011 (Quadro 3).

Quadro 3: Evolução da disponibilidade do acervo textual histórico(1)

\begin{tabular}{|l|c|c|c|c|c|c|c|c|}
\hline Ano & 1994 & 1995 & 2009 & 2010 & $\mathbf{2 0 1 1}$ & $\mathbf{2 0 1 2}$ & $\mathbf{2 0 1 3}$ & 2014 \\
\hline $\begin{array}{l}\text { Fundos e } \\
\text { coleções }\end{array}$ & 21 & 28 & 102 & 105 & 102 & 102 & 109 & 109 \\
\hline Disponível & 14 & 16 & 46 & 56 & 54 & 57 & 79 & 109 \\
\hline Indisponível & 7 & 12 & 56 & 49 & 48 & 45 & 30 & 0 \\
\hline$\%$ disponível & $67 \%$ & $57 \%$ & $45 \%$ & $53 \%$ & $53 \%$ & $56 \%$ & $72 \%$ & $100 \%$ \\
\hline \% indisponível & $33 \%$ & $43 \%$ & $55 \%$ & $47 \%$ & $47 \%$ & $44 \%$ & $28 \%$ & $0 \%$ \\
\hline
\end{tabular}

(1) O quantitativo de fundos de 2011 sofreu uma redução em relação a 2010, pois três fundos foram incorporados a outros já existentes.

Fonte: elaborado pela autora.

Com os controles exercidos pela equipe técnica e pela área de gestão, foi possível inserir outros sete fundos não previstos no escopo inicial, concluindo-se o projeto com o rendimento maior que o esperado, dentro do prazo previsto e com economia orçamentária de $12 \%$ em relação ao valor contratado.

O projeto concluído representa a superação do problema que comprometia a missão da COC e impedia a realização de iniciativas inerentes às atividades de instituições de custódia, tais como a difusão do acervo por meio da disponibilização de inventário completo, contendo a contextualização de cada fundo ou coleção. A contextualização é uma pequena biografia do acervo, onde são destacadas a relevância social, política e acadêmica do produtor, as características do acervo e a história de sua formação, visando despertar o interesse para novas pesquisas, exposições, processos educacionais, enfim, para um variado cardápio de possibilidades, já que os arquivos são fontes inesgotáveis de conhecimento e seus usos assumem múltiplas formas.

\section{Aprendizagem organizacional}

O monitoramento e a avaliação de projetos e programas são elementos essenciais para melhoria contínua do desempenho das organizações. O monitoramento tem a finalidade de viabilizar o gerenciamento e a tomada de decisões cotidianas relacionadas à implementação dos projetos e programas, comparando o que está sendo realizado com o que foi planejado. 
A avaliação é um processo mais complexo e consiste no julgamento do desempenho de um projeto ou programa de acordo com critérios preestabelecidos, identificando os impactos que seus resultados geraram.

No projeto de disponibilização do acervo, o monitoramento buscou acompanhar a produtividade mensal, corrigir falhas durante o processo, possibilitando o alcance da meta de disponibilização de $100 \%$ dos fundos acumulados até 2007. Já a avaliação, ainda com resultados parcialmente apurados, revelou que o projeto promoveu importantes movimentos de aprendizagem.

As equipes que atuaram diretamente no projeto foram beneficiadas com ações de aprendizagem que priorizaram o uso de normas e métodos destinados à organização de arquivos históricos. Os profissionais foram capacitados no uso da Norma Brasileira de Descrição Arquivística (Nobrade), aproximando historiadores e cientistas sociais dos critérios próprios para a organização de arquivos permanentes. Os documentalistas e arquivistas foram capacitados na metodologia desenvolvida pela COC para organização de fundos pessoais, aproximando-os dos conceitos utilizados no campo da história e da sociologia da ciência.

Além de ampliar e integrar conhecimentos específicos, essas capacitações despertaram para o potencial de desenvolvimento de qualificações nesses segmentos.

Durante a execução do projeto, foi ainda identificada a necessidade da produção de documentos de referência, resultando no Manual de organização de arquivos pessoais da Casa de Oswaldo Cruz, instrumento que apresenta todos os procedimentos adotados pelo DAD, desde a aquisição ou recolhimento até a disponibilização do acervo (COC, 2015).

Como oportunidade de melhoria, podemos destacar a necessidade da previsão da atividade de conservação do acervo no escopo inicial da contratação. No projeto realizado, essa atividade foi inserida com a execução dos serviços em curso, dificultando a sequência de algumas etapas que deveriam ter sido planejadas previamente. Com o planejamento adequado, a atividade de conservação pode ser melhor aproveitada, inclusive para capacitar profissionais no campo e formular documentos de referência.

O projeto trouxe também para o debate relevantes discussões conceituais acerca dos métodos mais adequados para organização de acervos singulares e que exigem abordagens específicas, como é o caso do acervo iconográfico. Essa discussão certamente refinará as práticas de organização do acervo permanente, atualizará os documentos de referência e enriquecerá experiências futuras.

\section{Considerações finais}

A gestão documental nas universidades, nos centros e instituições de pesquisa e em ambientes assistenciais do campo da saúde deve ocupar lugar de destaque nos debates acerca da necessária preservação dos acervos para o desenvolvimento da historiografia das ciências e da saúde no Brasil.

A gestão documental é simples, eficiente e apresenta custos menos onerosos do que os custos decorrentes da guarda e do tratamento das massas documentais, devendo ser 
considerada como a principal estratégia para organizações de custódia, especialmente diante da produção intensiva de documentos natodigitais que brevemente formará massas digitais.

Enquanto a disponibilização do acervo físico está sendo mantida em níveis adequados, é preciso continuar investindo em estratégias para melhoria do desempenho no campo da gestão dos documentos digitais. Os suportes digitais são altamente dependentes de software e de mídias de registro, leitura e armazenamento. Esses suportes entram em obsolescência rapidamente, sendo imperiosa a formulação de planos de preservação que garantam o acesso futuro às informações que estão sendo produzidas hoje.

Tudo indica que o domínio dos conceitos e dos requisitos técnicos relativos à documentação digital será um dos principais ativos intelectuais e de infraestrutura para as organizações de custódia de acervos científicos no futuro.

Anexo 1: Características do acervo disponibilizado

\begin{tabular}{|c|c|c|}
\hline Produtor & Conteúdo & Produção \\
\hline $\begin{array}{l}\text { Alfredo Norberto } \\
\text { Bica }\end{array}$ & $\begin{array}{l}\text { Reúne documentos textuais e iconográficos referentes à vida pessoal e à } \\
\text { trajetória profissional como médico sanitarista, pesquisador e gestor na área de } \\
\text { saúde pública, com ênfase na atuação em campanhas de combate e controle de } \\
\text { doenças no Brasil e no exterior, como peste, varíola e cólera. }\end{array}$ & 1920-2002 \\
\hline Anthony Leeds & $\begin{array}{l}\text { Reúne documentos textuais e iconográficos referentes à trajetória das pesquisas } \\
\text { desenvolvidas pelo titular e sua mulher, no Brasil e na América Latina, cujas } \\
\text { temáticas abrangeram as ocupações urbanas desordenadas e marginalizadas - } \\
\text { favelas, vilas, tugúrios e barriadas, as políticas habitacionais da região nas décadas } \\
\text { de } 1960 \text { a } 1980 \text { e a atuação dos movimentos sociais e dos órgãos governamentais } \\
\text { e não governamentais em favelas e outras formas de habitação popular no Brasil. }\end{array}$ & 1886-1989 \\
\hline $\begin{array}{l}\text { Aristides Lima } \\
\text { Verde }\end{array}$ & Com restrição. & \\
\hline $\begin{array}{l}\text { Assuerus } \\
\text { Hippolytus } \\
\text { Overmeer }\end{array}$ & Com restrição.(1) & \\
\hline $\begin{array}{l}\text { Astrogildo } \\
\text { Machado }\end{array}$ & $\begin{array}{l}\text { Reúne cartas, ofícios, recortes de jornais, noticiários, faturas, recibos, necrológicos, } \\
\text { certificados, bulas, fotografias, caderno de apontamentos, publicações, artigos } \\
\text { científicos, certificados e prospectos, entre outros documentos referentes à } \\
\text { vida pessoal e à trajetória profissional do titular como professor, pesquisador e } \\
\text { gestor do Instituto Oswaldo Cruz. Foi convidado por Carlos Chagas, pesquisador } \\
\text { do IOC, para compor a comissão enviada a Lassance para combater uma epidemia } \\
\text { de malária, e cujos trabalhos proporcionaram a Chagas a identificação de uma } \\
\text { nova espécie de protozoário, o Trypanosoma cruzi, causador da tripanossomíase } \\
\text { americana ou doença de Chagas. Entre } 1911 \text { e 1912, integrou duas expedições } \\
\text { científicas do IOC ao interior do país. Em 1919, foi nomeado para o cargo de } \\
\text { assistente efetivo do IOC, onde exerceu também, no período de } 1919 \text { a 1926, o } \\
\text { cargo de chefe de serviço substituto na ausência de Arthur Neiva e Alcides Godoy. } \\
\text { Em } 1939 \text {, em outra parceria com Alcides Godoy, fundou a empresa Produtos } \\
\text { Veterinários Manguinhos Ltda para fabricar e comercializar as vacinas contra } \\
\text { a peste da manqueira, que se tornou a principal fonte de receita do instituto } \\
\text { durante anos. }\end{array}$ & $1901-2002$ \\
\hline
\end{tabular}




\begin{tabular}{|c|c|c|}
\hline Produtor & Conteúdo & Produção \\
\hline $\begin{array}{l}\text { Augusto Cid de } \\
\text { Mello Perissé }\end{array}$ & $\begin{array}{l}\text { Reúne cartas, ofícios, cadernos de apontamento, declarações, recortes de } \\
\text { jornais, relatórios de pesquisa, publicações, artigos científicos, apostilas de curso, } \\
\text { cadernos de protocolo de pesquisa, fotografias, discursos e ensaios, entre outros } \\
\text { documentos referentes à vida pessoal e à trajetória profissional do titular como } \\
\text { professor e pesquisador na área de química orgânica e saúde pública, bem como } \\
\text { no tratamento e controle da hanseníase. }\end{array}$ & 1864-1994 \\
\hline Benjamin Gilbert & Com restrição. & \\
\hline $\begin{array}{l}\text { Carlos Chagas } \\
\text { Filho }\end{array}$ & $\begin{array}{l}\text { Reúne cartas, telegramas, ofícios, relatórios de atividades, atas, nomeações, } \\
\text { currículos, textos e artigos científicos, discursos, conferências, diplomas, } \\
\text { designações, declarações, apostilas, fotografias, caricaturas, periódicos, recortes } \\
\text { de jornais e folhetos, entre outros documentos referentes à vida pessoal e à } \\
\text { trajetória profissional do titular como pesquisador assistente, chefe de serviço } \\
\text { e diretor do Instituto Oswaldo Cruz, diretor da Diretoria Geral de Saúde Pública, } \\
\text { diretor do Departamento Nacional de Saúde Pública, professor catedrático da } \\
\text { Universidade do Rio de Janeiro, diretor do Centro Internacional de Leprologia, } \\
\text { membro do Comitê de Higiene da Liga das Nações e de diversas sociedades e } \\
\text { associações científicas, bem como representante do Brasil em eventos no exterior. }\end{array}$ & $1842-1959$ \\
\hline Celso Arcoverde & $\begin{array}{l}\text { Reúne cartas, ofícios, telegramas, bilhetes, discursos, conferências, recortes } \\
\text { de jornais, artigos científicos, informativos, relatórios de atividades, diários, } \\
\text { publicações, comunicações em eventos, mapas e fotografias, entre outros } \\
\text { documentos referentes à vida pessoal e à trajetória profissional do titular como } \\
\text { médico, pesquisador e gestor na área de saúde pública, com ênfase na atuação } \\
\text { em campanhas de combate e controle da peste e do tracoma. }\end{array}$ & $1922-2005$ \\
\hline Cláudio Amaral & $\begin{array}{l}\text { Reúne cartas, ofícios, relatórios, manuais, guias, discursos, informativos, recortes } \\
\text { de jornais, mapas, cartazes, fotografias e diapositivos, entre outros documentos } \\
\text { referentes à vida pessoal e à trajetória profissional do titular como médico } \\
\text { sanitarista. }\end{array}$ & $1942-2002$ \\
\hline $\begin{array}{l}\text { Conferência } \\
\text { Nacional de } \\
\text { Saúde, IX }\end{array}$ & $\begin{array}{l}\text { Reúne cartas, memorandos, ofícios, telegramas, discursos, recortes de jornais, } \\
\text { fotografias, relatórios de atividades, fichas de inscrição, transcrições de eventos, } \\
\text { moções, pronunciamentos, prospectos, listas de delegados e participantes, } \\
\text { regulamentos, dossiês temáticos, comunicações em eventos, cartazes, convites, } \\
\text { publicações e notas para imprensa, entre outros documentos referentes à } \\
\text { preparação, realização e repercussão da conferência. }\end{array}$ & 1974-1996 \\
\hline Eduardo Costa & $\begin{array}{l}\text { Reúne cartas, memorandos, ofícios, artigos científicos, discursos, fotografias, } \\
\text { estudos de caso, cartões-postais, trabalhos escolares, relatórios de atividades, } \\
\text { certificados, declarações, projetos de pesquisa, programas de eventos, apostilas } \\
\text { de curso, informativos, mensagens por fax, diapositivos, ensaios, cartazes, } \\
\text { recortes de jornais e revistas, entre outros documentos referentes à vida pessoal } \\
\text { e à trajetória profissional do titular como professor, pesquisador, dirigente e } \\
\text { membro de instituições científicas e político-partidárias no Brasil. }\end{array}$ & 1923-1998 \\
\hline Erney Camargo & $\begin{array}{l}\text { Reúne cartas, telegramas, jornais, noticiários, fotografias, memoriais, discursos, } \\
\text { informativos, revistas e recortes de jornais, entre outros documentos } \\
\text { referentes à vida pessoal e à trajetória profissional do titular como professor, } \\
\text { pesquisador, dirigente e membro de instituições e associações científicas e } \\
\text { acadêmicas. }\end{array}$ & 1936-2001 \\
\hline Estácio Monteiro & Com restrição. & \\
\hline $\begin{array}{l}\text { Estudo Nacional } \\
\text { de Despesa } \\
\text { Familiar }\end{array}$ & Com restrição. & \\
\hline
\end{tabular}




\begin{tabular}{|c|c|c|}
\hline Produtor & Conteúdo & Produção \\
\hline Eurico Villela & $\begin{array}{l}\text { Reúne cartas, cartões-postais, telegramas, recortes de jornais, fotografias, } \\
\text { discursos, artigos científicos, publicações, discursos e ensaios, entre outros } \\
\text { documentos referentes à vida pessoal e à trajetória profissional do titular como } \\
\text { pesquisador, professor e diretor de cursos sobre saúde pública, com ênfase no } \\
\text { estudo, combate e controle da doença de Chagas no Brasil. }\end{array}$ & 1905-1994 \\
\hline $\begin{array}{l}\text { Família Carneiro; } \\
\text { Paulo Carneiro }\end{array}$ & $\begin{array}{l}\text { Reúne cartas, memorandos, ofícios, telegramas, bilhetes, convites, artigos } \\
\text { científicos, discursos, conferências, fotografias, diplomas, certificados, declarações, } \\
\text { projetos de pesquisa, comunicações, programas de eventos, atas de reunião, } \\
\text { cartazes, recortes de jornais e revistas, entre outros documentos referentes à } \\
\text { vida pessoal e à trajetória profissional do titular como professor, pesquisador, } \\
\text { dirigente e membro de instituições científicas, acadêmicas e culturais, no Brasil e } \\
\text { no exterior. }\end{array}$ & $1786-2007$ \\
\hline Família Gouvea & Inserido no fundo Manoel Carlos Gouveia. & \\
\hline $\begin{array}{l}\text { Família Ozório de } \\
\text { Almeida }\end{array}$ & Com restrição. & \\
\hline Farmanguinhos & Com restrição. & \\
\hline $\begin{array}{l}\text { Felipe Nery } \\
\text { Guimarães }\end{array}$ & $\begin{array}{l}\text { Reúne fotografias referentes à trajetória do titular como pesquisador do Instituto } \\
\text { Oswaldo Cruz, coordenador do Programa de Erradicação da Bouba, chefe do } \\
\text { gabinete do Ministério da Saúde, bem como outras atividades profissionais e } \\
\text { homenagens a ele conferidas. }\end{array}$ & indefinido \\
\hline $\begin{array}{l}\text { Fonseca da } \\
\text { Cunha }\end{array}$ & Inserido na coleção de Documentos Avulsos. & \\
\hline Gustavo Riedel & $\begin{array}{l}\text { Reúne cartas, telegramas, fotografias, recortes de jornais e revistas, resoluções e } \\
\text { Diário Oficial referentes à vida pessoal e à trajetória profissional do titular como } \\
\text { psiquiatra, membro da Academia Nacional de Medicina e diretor da Colônia de } \\
\text { Alienadas do Engenho de Dentro e da Assistência a Psicopatas. }\end{array}$ & 1906-1935 \\
\hline $\begin{array}{l}\text { Haity } \\
\text { Moussatché }\end{array}$ & $\begin{array}{l}\text { Reúne cartas, telegramas, cartões-postais, publicações, artigos científicos, ensaios, } \\
\text { recortes de jornais, cadernos de protocolo de pesquisa e relatórios de atividades, } \\
\text { entre outros documentos referentes à vida pessoal e à trajetória profissional } \\
\text { do titular como professor e pesquisador nas áreas de fisiologia e farmacologia. }\end{array}$ & 1934-1996 \\
\hline Henry Jouval & Inserido na coleção de Documentos Avulsos. & \\
\hline Herman Lent & $\begin{array}{l}\text { Reúne agendas, artigos científicos, cadernos de apontamentos, cartas, cartões- } \\
\text { postais, cartões de visita, certificados, convites, currículo, diários, diplomas, } \\
\text { portarias, relatórios de atividades, diplomas, recortes de jornais e revistas, } \\
\text { informativos, entrevistas, livros de protocolo e registro, memorial descritivo, } \\
\text { projetos de pesquisa e fotografias, entre outros documentos referentes à } \\
\text { vida pessoal e à trajetória profissional do titular como pesquisador, gestor de } \\
\text { laboratórios, departamento, comissões e presidente da Fundação Oswaldo Cruz. }\end{array}$ & $1956-2010$ \\
\hline $\begin{array}{l}\text { Hildebrando } \\
\text { Monteiro } \\
\text { Marinho }\end{array}$ & $\begin{array}{l}\text { Reúne cartas, telegramas, ofícios, memorandos, diplomas, recortes de jornais, } \\
\text { fotografias, discursos, relatórios de atividades, comunicações em eventos, } \\
\text { informativos, artigos científicos, atas de reuniões, plantas e prospectos, entre } \\
\text { outros documentos referentes à vida pessoal e à trajetória profissional do titular } \\
\text { como médico, professor e gestor nas áreas de hematologia e hemoterapia. }\end{array}$ & 1913-2006 \\
\hline $\begin{array}{l}\text { Hospital Escola } \\
\text { São Francisco de } \\
\text { Assis }\end{array}$ & Inserido na coleção do Centro de Memória da Faculdade Nacional de Medicina. & \\
\hline
\end{tabular}




\begin{tabular}{|c|c|c|}
\hline Produtor & Conteúdo & Produção \\
\hline Hugo Laemmert & $\begin{array}{l}\text { Reúne cartas, certificados, diplomas, recortes de jornais, artigos científicos, } \\
\text { publicações e ensaios, entre outros documentos referentes à trajetória } \\
\text { profissional do titular como pesquisador em estudos sobre o comportamento } \\
\text { do vírus amarílico na mata, seus vetores e depositários foram desenvolvidos no } \\
\text { Serviço de Febre Amarela (1935-1939), mantido cooperativamente pela Fundação } \\
\text { Rockefeller e o governo brasileiro, no Serviço de Estudos e Pesquisas sobre a } \\
\text { Febre Amarela (1940-1949), administrado pelo Ministério da Educação e Saúde, } \\
\text { e no IOC (1950-1962). Inclui atividades de gestão de laboratórios, professor do } \\
\text { Curso de Bacteriologia, Parasitologia e Imunologia. }\end{array}$ & $1932-1963$ \\
\hline Jorge Ferreira & Com restrição. & \\
\hline Lopes Pontes & 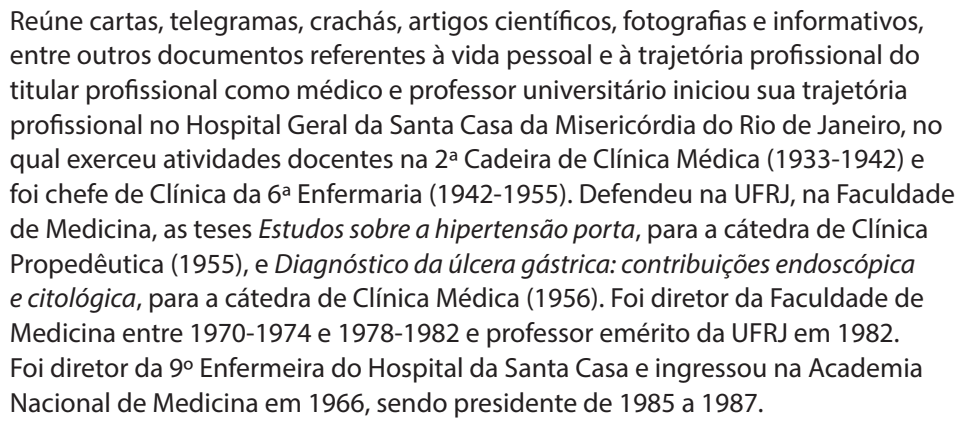 & 1907-1983 \\
\hline José Jurberg & $\begin{array}{l}\text { Reúne cartas, memorandos, ofícios, artigos científicos, discursos, fotografias, } \\
\text { desenhos, relatórios de atividades, certificados, declarações, programas de } \\
\text { eventos, apostilas de curso, informativos, recortes de jornal e revistas, entre outros } \\
\text { documentos referentes à vida pessoal e à trajetória profissional do titular como } \\
\text { pesquisador, professor, gestor e membro de instituições e associações científicas, } \\
\text { entre elas o Instituto Oswaldo Cruz e a Sociedade Brasileira de Zoologia. }\end{array}$ & $1912-2007$ \\
\hline $\begin{array}{l}\text { Laerte de } \\
\text { Andrade }\end{array}$ & $\begin{array}{l}\text { Reúne cartas, ofícios, fotografias, cartões-postais, publicações, artigos científicos, } \\
\text { recortes de jornal, certificados, diplomas, relatórios de atividades, ensaios, revistas } \\
\text { e projetos de pesquisa, entre outros documentos referentes à vida pessoal e } \\
\text { à trajetória do titular como professor, pesquisador e gestor na área de saúde } \\
\text { pública, com ênfase no estudo e controle da tuberculose. }\end{array}$ & 1932-1996 \\
\hline $\begin{array}{l}\text { Lejeune de } \\
\text { Oliveira }\end{array}$ & $\begin{array}{l}\text { Reúne carteiras de identidade, designações, declarações, cartas, certificados, } \\
\text { currículos, diplomas, artigos científicos, ofícios, relatórios de atividades, ensaios, } \\
\text { revistas, atas de defesa de dissertação e listas de publicações, entre outros } \\
\text { documentos referentes à vida pessoal e à trajetória profissional do titular como } \\
\text { pesquisador e professor da área de saúde pública, sendo os principais objetos de } \\
\text { seus estudos os seres que habitam o meio aquático, de águas doces ou marinhas. }\end{array}$ & 1921-1991 \\
\hline Liga das Nações & $\begin{array}{l}\text { Reúne projetos, revistas, resoluções, atas de reunião, informativos, publicações } \\
\text { e relatórios de atividades, entre outros documentos referentes às atividades da } \\
\text { Liga das Nações na área da saúde, incluindo o período em que Carlos Chagas } \\
\text { foi membro do Comitê de Higiene da instituição (1922-1934) e de entidades do } \\
\text { sistema da Organização das Nações Unidas. }\end{array}$ & 1921-1954 \\
\hline Lourival Ribeiro & $\begin{array}{l}\text { Reúne cartas, ofícios, teses, artigos científicos, currículos, diplomas, certificados, } \\
\text { atas, recortes de jornais e revistas, fotografias, programas de eventos, discursos, } \\
\text { relatórios de atividades e informativos, entre outros documentos referentes à } \\
\text { vida pessoal e à trajetória profissional do titular como médico tisiologista e gestor } \\
\text { de instituições de ensino e saúde pública. }\end{array}$ & 1840-1992 \\
\hline
\end{tabular}




\begin{tabular}{|c|c|c|}
\hline Produtor & Conteúdo & Produção \\
\hline Luís Fontenelle & $\begin{array}{l}\text { Reúne cartas, ofícios, portarias, declarações, memorandos, projetos de pesquisa, } \\
\text { relatórios, contratos, artigos científicos, recortes de jornais e fotografias, entre } \\
\text { outros documentos referentes à vida pessoal e à trajetória profissional do titular } \\
\text { como antropólogo e professor. }\end{array}$ & $1950-2008$ \\
\hline $\begin{array}{l}\text { Manoel Carlos } \\
\text { Gouveia }\end{array}$ & $\begin{array}{l}\text { Reúne telegramas, cartas, fotografias, recortes de jornal, portarias, panfletos, } \\
\text { estatutos, livros, cartões, relatórios de atividades, memorandos, atas de reunião, } \\
\text { discursos, entre outros documentos referentes à vida pessoal e à trajetória do } \\
\text { titular como prefeito municipal de lguatu e diretor do Hospital de Santo Antônio } \\
\text { dos Pobres. }\end{array}$ & 1895-1999 \\
\hline $\begin{array}{l}\text { Marcolino } \\
\text { Candau }\end{array}$ & Com restrição. & \\
\hline Mário Aragão & $\begin{array}{l}\text { Reúne passaportes, carteiras de trabalho, cartas, fotografias, recortes de jornais, } \\
\text { certificados, ofícios, memorandos, artigos científicos, contratos de trabalho e } \\
\text { relatórios de atividades, entre outros documentos referentes à vida pessoal e à } \\
\text { trajetória profissional do titular como professor e pesquisador de instituições } \\
\text { científicas onde realizou pesquisas sobre microclimáticas, bromelecidas e o raio } \\
\text { de voo de mosquitos, nos estados do Paraná e Santa Catarina. Foi pesquisador } \\
\text { do Instituto Nacional de Endemias Rurais (Ineru). Entre } 1964 \text { e 1968, trabalhou } \\
\text { na Universidade de El Salvador como professor e diretor do Departamento } \\
\text { de Ciências Biológicas. Em 1970, foi assessor do Instituto de Conservação da } \\
\text { Natureza do estado da Guanabara. Em 1975, entrou para o quadro de servidores } \\
\text { da Fundação Oswaldo Cruz, lotado no Instituto de Endemias Rurais, nova } \\
\text { denominação do Ineru, que passou para a estrutura organizacional da instituição } \\
\text { após a extinção do Departamento Nacional de Endemias Rurais. De } 1976 \text { a 1978, } \\
\text { fez parte do Projeto RADAMBRASIL na condição de assessor técnico da Divisão } \\
\text { de Uso Potencial da Terra. Ainda na década de 1970, integrou o Conselho de } \\
\text { Valorização de Parques do Instituto Brasileiro de Desenvolvimento Florestal, como } \\
\text { representante do Ministério das Minas e Energia (1976), e o Grupo de Trabalho do } \\
\text { Conselho Nacional de Saúde responsável pela elaboração do manual “Praguicidas } \\
\text { em saúde pública” (1979). Em 1980, transferiu-se para a Escola Nacional de Saúde } \\
\text { Pública, onde atuou no Departamento de Ciências Biológicas. }\end{array}$ & 1964-2013 \\
\hline $\begin{array}{l}\text { Mário Vianna } \\
\text { Dias }\end{array}$ & $\begin{array}{l}\text { Reúne teses, relatórios de atividades, projetos, discursos, recortes de jornais, } \\
\text { conferências, artigos científicos, revistas e fotografias, entre outros documentos } \\
\text { referentes à vida pessoal e à trajetória profissional do titular como professor } \\
\text { e pesquisador do Instituto Oswaldo Cruz e de outras instituições de ensino e } \\
\text { pesquisa do Rio de Janeiro. }\end{array}$ & 1838-1987 \\
\hline $\begin{array}{l}\text { Oliveira } \\
\text { Rodrigues }\end{array}$ & $\begin{array}{l}\text { Reúne cartas, ofícios, memorandos, relatórios de atividades, declarações, atas } \\
\text { de reunião, resumos, recortes de jornais, artigos científicos, publicações e } \\
\text { informativos, entre outros documentos referentes à trajetória profissional do } \\
\text { titular como pesquisador e membro de associações científicas. Sua trajetória } \\
\text { científico-acadêmica esteve ligada aos estudos de helmintos parasitos de } \\
\text { vertebrados desenvolvidos no IOC, onde atuou como bolsista de Lauro Travassos } \\
\text { e J. F. Teixeira de Freitas (1959-1962), biologista (1962), pesquisador (1969) e } \\
\text { curador da Coleção Helmintológica (1977-1981). Ainda no IOC, foi chefe da Seção } \\
\text { de Helmintologia da Divisão de Zoologia e do Laboratório de Helmintologia do } \\
\text { Departamento de Zoologia Médica (1968-1974). Em 1970, na cidade de Lisboa, } \\
\text { realizou estágios no Laboratório de Entomologia e Helmintologia da Escola } \\
\text { Nacional de Saúde Pública e de Medicina Tropical e no Laboratório dos Serviços } \\
\text { Veterinários dos Portos de Pesca. Foi membro da Sociedade de Biologia do Rio de } \\
\text { Janeiro, da Associação de Biologia do Rio de Janeiro, da Sociedade dos Amigos } \\
\text { do Museu Nacional, da Associação de Docentes, Pesquisadores e Tecnologistas da } \\
\text { Fundação Oswaldo Cruz e da Sociedade Brasileira para o Progresso da Ciência. }\end{array}$ & 1906-1996 \\
\hline
\end{tabular}




\begin{tabular}{|c|c|c|}
\hline Produtor & Conteúdo & Produção \\
\hline $\begin{array}{l}\text { Paulo de Almeida } \\
\text { Machado }\end{array}$ & Com restrição. & \\
\hline Reinout Altman & $\begin{array}{l}\text { Reúne cartas, relatórios de atividades, publicações, artigos científicos, recortes } \\
\text { de jornais e fotografias, entre outros documentos referentes à vida pessoal e à } \\
\text { trajetória profissional do titular como pesquisador da área da saúde pública. }\end{array}$ & $1916-1990$ \\
\hline $\begin{array}{l}\text { Romualdo } \\
\text { Dâmaso }\end{array}$ & $\begin{array}{l}\text { Reúne cartas, ofícios, relatórios de atividades, programas de eventos, publicações, } \\
\text { portarias, certificados, revistas, artigos científicos e recortes de jornais, entre } \\
\text { outros documentos referentes à vida pessoal e à trajetória profissional do } \\
\text { titular como professor e pesquisador da área das ciências sociais aplicadas à } \\
\text { saúde pública. }\end{array}$ & 1909-1997 \\
\hline $\begin{array}{l}\text { Rubens da Rocha } \\
\text { Paranhos }\end{array}$ & Com restrição. & \\
\hline Sávio Antunes & $\begin{array}{l}\text { Reúne livros, cartas, recortes de jornais e revistas, fichas de leitura, cadernos de } \\
\text { apontamentos, apostilas, relatórios de atividades, ensaios, artigos científicos, } \\
\text { discursos, fotografias, entre outros documentos referentes à vida pessoal e } \\
\text { à trajetória profissional do titular como professor de matemática, estatística e } \\
\text { ciência da informação e enquanto chefe de departamento da Escola Nacional de } \\
\text { Saúde Pública da Fundação Oswaldo Cruz. }\end{array}$ & 1909-1985 \\
\hline Sérgio Góes & Inserido no fundo Casa de Oswaldo Cruz. & \\
\hline $\begin{array}{l}\text { Sociedade } \\
\text { Brasileira de } \\
\text { Biologia }\end{array}$ & Inserido no fundo Oliveira Rodrigues. & \\
\hline $\begin{array}{l}\text { Sociedade } \\
\text { Brasileira de } \\
\text { Parasitologia }\end{array}$ & $\begin{array}{l}\text { Reúne cartas, memorandos, ofícios, convites, estatutos, livros de sócios, atas } \\
\text { de reuniões, informativos, recibos de pagamentos e informativos, entre outros } \\
\text { documentos referentes às atividades desenvolvidas pela instituição. }\end{array}$ & 1965-1997 \\
\hline $\begin{array}{l}\text { Superintendência } \\
\text { Operacional; } \\
\text { Programa } \\
\text { Nacional de } \\
\text { Imunizações }\end{array}$ & $\begin{array}{l}\text { Os arquivos da Superintendência Operacional e do Programa Nacional de } \\
\text { Imunizações formam um único conjunto. }\end{array}$ & \\
\hline $\begin{array}{l}\text { Szachna } \\
\text { Cynamon }\end{array}$ & $\begin{array}{l}\text { Reúne cartas, memorandos, ofícios, relatórios de atividades, manuais, mapas, } \\
\text { plantas, comunicações em eventos, atas de reuniões, projetos, artigos científicos, } \\
\text { mensagens por fax, certificados e fotografias, entre outros documentos referentes } \\
\text { à vida pessoal e à trajetória profissional do titular como engenheiro, professor e } \\
\text { pesquisador na área de saúde pública. }\end{array}$ & 1916-2007 \\
\hline $\begin{array}{l}\text { Teixeira de } \\
\text { Freitas }\end{array}$ & Com restrição. & \\
\hline $\begin{array}{l}\text { Virgínia } \\
\text { Portocarrero }\end{array}$ & $\begin{array}{l}\text { Reúne documentos produzidos e acumulados pela titular do arquivo ao longo } \\
\text { de sua trajetória pessoal e profissional, incluindo os documentos relativos à sua } \\
\text { formação profissional e acadêmica. São fotografias, correspondência, recortes de } \\
\text { jornais, panfletos, ilustrações, desenhos, dentre outros, com destaque para um } \\
\text { diário sobre a sua atuação como enfermeira da Força Expedicionária Brasileira } \\
\text { (FEB) durante a participação brasileira na Segunda Guerra Mundial. }\end{array}$ & $1917-2010$ \\
\hline
\end{tabular}




\begin{tabular}{|c|l|c|}
\hline \multicolumn{1}{|c|}{ Produtor } & \multicolumn{1}{c|}{ Conteúdo } & Produção \\
\hline Walter Mendes & $\begin{array}{l}\text { Reúne cartas, cartões-postais, fotografias, publicações, recortes de jornais, } \\
\text { revistas, ensaios, resoluções, relatórios de atividades, apresentações de obras, } \\
\text { artigos científicos, folhetos e informativos, entre outros documentos referentes à } \\
\text { trajetória profissional do titular como médico tisiologista e diretor de instituições } \\
\text { públicas da área da saúde, como o Hospital Sanatório de São Sebastião, o Hospital } \\
\text { Sanatório Torres Homem e o Departamento de Tuberculose da Prefeitura do } \\
\text { Distrito Federal. }\end{array}$ & $1944-1968$ \\
\hline
\end{tabular}

(1) Os fundos com conteúdo restrito estão em tratamento técnico, conforme consulta realizada em 10 mar. 2018 na Base Arch (<http://arch.coc.fiocruz.br $>$ ).

Fontes: Base Arch/Departamento de Arquivo e Documentação da Casa de Oswaldo Cruz e Academia Brasileira de Ciências.

\section{AGRADECIMENTOS}

Dirijo sinceros agradecimentos à Casa de Oswaldo Cruz, porque somente em organizações que reconhecem o papel da gestão - a chamada área "meio", pouco reconhecida nos resultados finais das organizações é possível realizar uma atividade integrada entre a área finalística e a área de gestão. Agradeço a Maria da Conceição Castro e Paulo Roberto Elian dos Santos pela revisão dos conceitos descritos neste artigo. Reputo a essas pessoas somente os acertos desta publicação. Agradeço também à equipe do Departamento de Arquivo e Documentação e à equipe de Gestão da Casa de Oswaldo Cruz pelo comprometimento e dedicação.

\section{NOTAS}

${ }^{1}$ As pesquisas com genoma humano e com o acelerador de partículas $L H C$ estão na fronteira do conhecimento, configurando a new big science, dado o imenso volume de dados gerados e compartilhados que influenciaram na definição do conceito de big data.

${ }^{2}$ O Sistema de Gestão de Documentos e Arquivos (Sigda) foi instituído pela Portaria PR 353/2009, com o objetivo assegurar de forma eficiente a produção, administração, manutenção e destinação dos documentos gerados pela Fiocruz e o estabelecimento de políticas e processos de gestão arquivística, condição necessária para a adequada formação e uso do patrimônio documental.

${ }^{3} \mathrm{O}$ caderno de protocolo é o documento que descreve as rotinas da função de pesquisa em sua fase de desenvolvimento e serve de testemunho das experiências realizadas, dos dados e resultados obtidos, sendo, portanto, documento de arquivo.

${ }^{4}$ A vacina contra a peste da Manqueira, que ataca principalmente bovinos jovens e ocasionalmente ovinos, foi o primeiro produto veterinário registrado no Brasil. Sucesso de vendas, essa e outras receitas permitiram a autossustentação do instituto durante seus primeiros vinte anos de existência.

${ }^{5} \mathrm{O}$ instituto formava seus próprios quadros de pessoal, tendo o curso de aplicação como porta de entrada na carreira de pesquisa. O Curso de Aplicação de Manguinhos era reconhecido pela rigidez das disciplinas, exigia dedicação integral e não era remunerado.

${ }^{6}$ O decreto 66.624/1970 transformou o Instituto Oswaldo Cruz em Fundação Oswaldo Cruz, incorporando as seguintes estruturas do Ministério da Saúde: Escola Nacional de Saúde Pública (Ensp), Instituto Fernandes Figueira, Instituto Nacional de Endemias Rurais (Ineru), Instituto Evandro Chagas de Belém (reintegrado à Fundação Serviços de Saúde Pública pelo decreto 75.967/1975) e Instituto de Leprologia.

${ }^{7} \mathrm{O}$ objetivo de transformar o instituto em fundação atendia ao interesse de alcançar as flexibilidades administrativas previstas para as fundações e autarquias públicas no decreto 200/1967. Essas flexibilidades foram extintas pela Constituição Federal Brasileira em 1988. 


\section{REFERÊNCIAS}

AZEVEDO, Nara; HAMILTON, Wanda. Um estranho no ninho: memórias de um expresidente da Fiocruz. História, Ciências, SaúdeManguinhos, v.8, n.1, p.237-264. 2001.

BERNARDES, Ieda Pimenta.

Como avaliar documentos de arquivo. São Paulo: Arquivo do Estado. 1998.

COC.

Casa de Oswaldo Cruz. Fundo Casa de Oswaldo Cruz. 1986-2015. Seção Administrativa. Documentos textuais: reúne projetos de pesquisa, formulários e relatórios técnicos, entre outros documentos, referentes aos projetos Organização e ampliação da documentação. 1986-2015.

COC.

Casa de Oswaldo Cruz. Manual de organização de arquivos pessoais. Rio de Janeiro: Fiocruz/ COC. Disponível em: <http://www.coc.fiocruz. br/images/PDF/manual_organizacao_arquivos_ fiocruz.pdf $>$.Acesso em: 20 jul. 2017. 2015.

COC.

Casa de Oswaldo Cruz. Política de preservação e gestão de acervos culturais das ciências e da saúde. Rio de Janeiro: Fiocruz/COC. Disponível em: <http://www.coc.fiocruz.br/images/PDF/ politica_preservacao_gestao_acervos_coc.pdf $>$. Acesso: 22 jan. 2017. 2013.

COC.

Casa de Oswaldo Cruz. Guia do acervo, 2. Edição revisada e ampliada. Rio de Janeiro: Fiocruz. 2009.

COSTA, André Luiz Maiocchi Alves.

Desafios para longevidade saudável de uma organização brasileira do setor saúde: o caso Fiocruz. Dissertação (Mestrado) - Instituto de Pós-Graduação e Pesquisa em Administração, Universidade Federal do Rio de Janeiro, Rio de Janeiro. Disponível em: <http://www.coppead. ufrj.br/upload/publicacoes/Andre_Costa.pdf>. Acesso em: 18 set. 2016. 2014.

CRUZ, Emilia Barroso.

Manual de gestão de documentos. Belo Horizonte: Secretaria de Estado de Cultura de Minas Gerais, Arquivo Público Mineiro. Disponível em: <http://simagestao.com.br/wp-content/ uploads/2016/02/Manual-de-Gestao-deDocumentos.pdf>. Acesso: 28 set. 2016. 2013.

E-ARQ Brasil.

Modelo de requisitos para sistemas informatizados de gestão arquivística de documento. Câmara Técnica de documentos eletrônicos. 1.1 versão. Rio de Janeiro: Arquivo Nacional. 2011.
GESPÚBLICA.

Guia referencial para medição de desempenho e manual para construção de indicadores.

Disponível em: <http://www.gespublica.gov.br>. Acesso em: 12 nov. 2016.19 jun. 2010.

LENT, Herman.

O massacre de Manguinhos. Rio de Janeiro: Avenir Editora. 1978.

PIRES-ALVES, Fernando A.; SANTOS Ricardo Augusto dos; HAMILTON, Wanda Suzana. Acervo da Casa de Oswaldo Cruz. História, Ciências, Saúde - Manguinhos, v.1, n.1, p.145-152. Jul.-out. 1994.

PONTE, Carlos Fidelis.

Fundação pública e autonomia: desafios e perspectivas institucionais. Documento do sétimo Congresso Interno da Fundação Oswaldo Cruz. Disponível em: <http://congressointerno. fiocruz.br/sites/congressointerno.fiocruz. br/files/documentos/VII\%20Congresso $\% 20$ Interno_\%20Fun\%C3\%A7\%C3\%A30\%20 p\%C3\%BAblica\%20e\%20autonomia vers\%C3\%A3o\%20para\%20CD_\%2029-102015.pdf>. Acesso em: 12 jan. 2017. 29 out. 2015.

PONTE, Carlos Fidelis.

Bio-Manguinhos 30 anos: a trajetória de uma instituição pública de ciência e tecnologia. Cadernos de História da Ciência - Instituto Butantan, v.3, n.1, p.35-138. 2007.

RIBEIRO, Fernanda.

Antes e para além do Arquivo Nacional: ruturas e continuidades. In: Rosa, Maria de Lurdes (Org.). Arquivos de família, século XIII-XX: que presente, que futuro? Lisboa: Instituto de Estudos Medievais; Centro de História de Além-Mar. Disponível em: <https://repositorioaberto.up.pt/bitstream/10216/63555/2/ fernandaribeiro000163653.pdf>. Acesso em: 28 de jan. 2017. 2012.

RIBEIRO, Fernanda. Sem gestão de informação não há memória que perdure. Porto: Faculdade de Letras da Universidade do Porto. Disponível em: <https:// www.publico.pt/culturaipsilon/jornal/semgestao-de-informacao-nao-ha-memoria-queperdure-182956>. Acesso em: 28 de jan. 2017. 14 jan. 2004.

SANTOS, Paulo Roberto Elian dos. Uma abordagem arquivística: os documentos de um laboratório de ciências biomédicas. História, Ciências e Saúde - Manguinhos, v.19, n.1, p.303323. 2012.

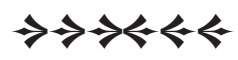

